\title{
Measurement of exposure to personnel performing shielding evaluations
}

\author{
Leland Page, Cristina Dodge, Guang Li, Richard Wendt \\ Department of Imaging Physics, The University of Texas MD Anderson Cancer Center, Houston, TX, USA.
}

Received March 19, 2014; Published Online April 08, 2014

[Presented at the Young Investigator's Symposium at the 2014 Annual Meeting of

Southwest Chapter of American Association of Physicists in Medicine (AAPM) in San Antonio, Texas, USA]

\section{Conference Proceeding}

\begin{abstract}
Purpose: Determine the exposure to personnel accrued while performing shielding evaluations of diagnostic facilities.

Methods: Shielding inspections were performed at three sites: a small animal imaging facility, an imaging center consisting of general $\mathrm{x}$-ray, CT, and PET/CT rooms, and a cardiac catheterization lab. The small animal facility was evaluated using two $20 \mathrm{mCi}$ Tc-99m uncollimated sources. The imaging center was evaluated using a $20 \mathrm{mCi}$ source of $\mathrm{F}-18$ for the PET/CT room and a collimated $25 \mathrm{mCi}$ source of Tc-99m for the CT and $\mathrm{x}$-ray rooms. The catheterization lab was evaluated using an uncollimated $35 \mathrm{mCi}$ vial of Tc-99m. Electronic personal dosimeters (Rados RAD-60R, RADOS Technology Oy Turku, Finland) were worn by each of the personnel involved in performing shielding inspections. The cumulative exposure reading from the dosimeter for each surveyor was recorded.
\end{abstract}

Results: The surveyor who positioned the open source at the small animal facility had an exposure reading of $3.5 \mathrm{mR}$ in 5.5 hours. Those who were outside the room surveying the barriers had readings of 0 and $0.1 \mathrm{mR}$ in 5 hours. For the cath lab, the surveyor positioning the source had a reading of $0.4 \mathrm{mR}$ in 30 minutes, while those outside had readings of $0 \mathrm{mR}$. At the imaging center all personnel surveying the PET/CT room with an open F-18 source had readings of 2.0, 1.1, and $2.9 \mathrm{mR}$ in 4 hours. Surveys of the CT and general radiography rooms with a collimated Tc-99m source had readings of $1.2,0.9$, and $0.2 \mathrm{mR}$ in 5 hours.

Presenting author: Leland Page; Department of Imaging Physics, The University of Texas MD Anderson Cancer Center, Houston, TX, USA.

Cite this article as:

Page L, Dodge C, Li G, Wendt R. Measurement of exposure to personnel performing shielding evaluations. Int J Cancer Ther Oncol 2014; 2(2):020230. DOI: 10.14319/ijcto.0202.30
Conclusion: The surveyors who were in the room with the sources had the highest exposures. Using a higher energy source (F-18) also led to higher exposures. By using a collimated source, the time to measure each barrier for penetrations was increased, but the surveyors' exposures were lower.

Innovation/Impact: This study provides feedback on the exposure levels received by personnel while performing shielding evaluations of diagnostic facilities. In particular, it highlights which methods contribute to higher exposures and techniques that can be used to minimize the exposure of the surveyors.

Key Results: The exposure readings for the personnel at each facility along with the time spent surveying are shown in Table 1 below. When using open sources of Tc-99m and a higher energy source (F-18), the exposures to personnel per time spent were two to three times higher than the exposures per time spent while using a collimated source of Tc-99m. Photos of the collimated and uncollimated sources are shown below in Figure 1.

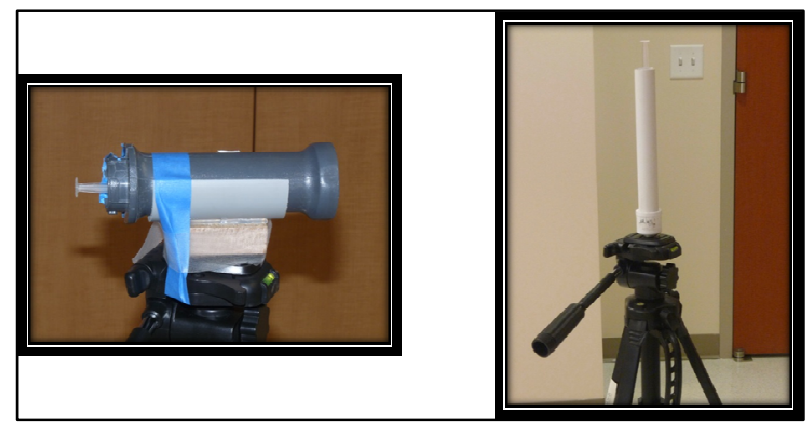

FIG. 1: Photos of the sources used for shielding inspection. The collimated source (left) was kept in a lead pig and attached to a holder on a tripod. The uncollimated source (right) was placed into a PVC pipe attached to a tripod. 
TABLE 1: Exposure readings from Rados personal dosimeters worn by personnel and time spent participating in shielding surveys of three diagnostic facilities.

\begin{tabular}{|c|c|c|c|c|c|c|c|}
\hline \multirow[b]{3}{*}{ Facility } & \multirow{3}{*}{$\begin{array}{r}\text { Source } \\
\text { Personnel }\end{array}$} & \multicolumn{6}{|c|}{ Exposure Reading (mR) } \\
\hline & & \multicolumn{4}{|c|}{ Tc-99m } & \multicolumn{2}{|c|}{ F-18 } \\
\hline & & Open & Time (hrs) & Collimated & Time (hrs) & Open & Time (hrs) \\
\hline \multirow[t]{3}{*}{ Small Animal } & 1 & 3.5 & 5.5 & - & - & - & - \\
\hline & 2 & - & - & 0 & 5 & - & - \\
\hline & 3 & - & - & 0.1 & 5 & - & - \\
\hline \multirow[t]{3}{*}{ Cath Lab } & 1 & 0 & 0.5 & - & - & - & - \\
\hline & 2 & 0 & 0.5 & - & - & - & - \\
\hline & 3 & 0.4 & 0.5 & - & - & - & - \\
\hline \multirow[t]{3}{*}{ Imaging Center } & 1 & - & - & 1.2 & 5 & 2 & 4 \\
\hline & 2 & - & - & 0.9 & 5 & 1.1 & 4 \\
\hline & 3 & - & - & 0.2 & 5 & 2.9 & 4 \\
\hline
\end{tabular}

